\title{
LUGAR E CONTEXTO: ALGUNS APONTAMENTOS SOBRE A POLÍTICA LOCAL NO BRASIL ${ }^{2}$
}

\author{
Jean Lucas Macedo Fernandes ${ }^{3}$
}

\begin{abstract}
RESUMO
O objetivo do artigo é discutir alguns dos argumentos que defendem a importância da política local enquanto possível foco analítico para a compreensão dos processos políticos. Trata-se de colocar, em primeiro plano, a dimensão do lugar e do contexto como conceitos cruciais para se entender as dinâmicas políticas locais e suas especificidades. A partir da descrição das considerações da literatura acerca do tema, e trazendo alguns levantamentos sobre o caso brasileiro, como forma de reforçar o argumento sobre a relevância do poder local, a conclusão principal é a de que há um ganho analítico fundamental quando se leva em conta a perspectiva contextual. No Brasil, onde mudanças importantes no papel dos municípios foram observadas a partir da Constituição de 1988, essa perspectiva se torna bastante elucidativa, na medida em que a política local apresenta um ambiente altamente complexo e diverso, com desafios a serem enfrentados.
\end{abstract}

Palavras-chave: política local; lugar; contexto; municípios.

\begin{abstract}
The article aims to discuss some arguments in favor of the importance of local politics as a possible analytical focus to comprehend political processes. It is about to put, in the first place, the dimension of place and context as crucial concepts to understand local politics' dynamics and specificities. Describing the considerations of the literature concerning the topic, and bringing some discussions about the Brazilian case as a way to reinforce the argument about the relevance of local power, the conclusion is that there is a fundamental analytical gain when the contextual perspective is adopted. With Brazil's important changes in the roles attributed to the municipalities since the 1988 Constitution, this perspective becomes even clearer, since local politics presents a complex and diverse environment, with challenges to be faced.
\end{abstract}

Keywords: local politics; place; context; cities.

\section{RESUMEN}

El objetivo del presente artículo es discutir algunos de los argumentos que defienden la importancia de la política local como un posible enfoque analítico para la comprensión de procesos políticos. Se trata de colocar en primer plano, la dimensión del lugar y del contexto como conceptos clave para entender las dinámicas de políticas locales y sus especificidades. La metodología planteada, es básicamente, descripción de consideraciones de la literatura - la cual busca construir una contextualización para responder al objetivo planteado y al mismo tiempo, articularlo con el fin de producir una referencia teórica. Recopilando algunas informaciones de la literatura sobre el caso de Brasil, como una manera de reforzar el argumento sobre la relevancia del poder local, la conclusión principal resulta en que existe una ganancia analítica cuando se tiene en consideración la perspectiva contextual. En Brasil, los principales cambios en el papel de los municipios fueron observados a partir de la Constitución de 1988, lo que demuestra una perspectiva bastante esclarecedora, en la medida en que la política local representa un ambiente altamente complejo y diverso, con desafíos por afrontar.

Palabras clave: política local; lugar; contexto; municipios.

\section{A POLÍTICA LOCAL COMO OBJETO DE ESTUDO}

A política local é um tema vasto e plural, visto que possibilita um olhar analítico mais preciso sobre os fenômenos políticos e sociais. Ao tratarmos de governos e dinâmicas locais, estamos nos remetendo, de modo geral, ao funcionamento dos governos municipais,

\footnotetext{
${ }^{1}$ Enviado: 19/04/2016

Aceito: 11/04/2017

${ }^{2}$ DOI: $10.5380 /$ recp.v8i1.46413

${ }^{3}$ Possui Licenciatura e Bacharelado em Ciências Sociais (habilitação em Ciência Política), pela Universidade Estadual de Campinas (IFCH/UNICAMP). Membro do Grupo de Estudos de Política Brasileira (PolBrás). Atualmente é mestrando em Ciência Política do IFCH/UNICAMP.
} 
seus atores políticos (prefeitos, vereadores e sociedade civil), e suas relações com as demais esferas governamentais. As cidades podem ser melhor apreendidas se concebidas enquanto atores sociais e políticos, na medida em que realizam articulações entre sociedade civil e instituições políticas, assumindo, assim, responsabilidades perante os cidadãos e as diferentes instâncias do Estado (CASTELLS E BORJA, 1996). Além disso, as cidades são também frutos de relações espaciais perante suas redes urbanas, espaços intra-urbanos e demais rearranjos que não se dão somente pelo enfoque político, mas também econômico, social e cultural (CORRÊA, 2008; VILLAÇA, 2011). Nesse sentido, o contexto local está integrado a contextos e lugares mais amplos, como os estados e a União, sendo um componente importante para se compreender os processos vivenciados na política nacional (TROUNSTINE, 2009).

As cidades possibilitam aos cidadãos formarem concepções acerca de suas comunidades (CANCLINI, 2002), bem como redes sociais e comunitárias, que por sua vez criam vínculos culturais e identidades coletivas (CASTELLS E BORJA, 1996). Assim, o conceito de lugar torna-se o elemento fundamental para se compreender a formação das preferências políticas individuais, a adoção de determinadas estratégias e medidas pelas instituições, e a maneira como este território específico impacta nas dinâmicas políticas ressaltam-se, aqui, principalmente: eleições, processos decisórios, formulação e implementação de políticas públicas, participação cidadã, estratégias partidárias, dentre outros. É a partir do contexto e da dimensão do território que se torna possível assimilar melhor o poder local.

Terron (2012) aponta para o notável crescimento do interesse pela geografia eleitoral na Ciência Política brasileira ${ }^{4}$ e também latino-americana. O propósito das diversas ações que têm ocorrido nos últimos anos, voltadas para o incentivo às agendas de pesquisa sobre a temática, é "promover a reinserção do espaço, enquanto conceito e método, na agenda de estudos sociopolíticos" (TERRON, 2012, p. 9).

Sob essa perspectiva analítica, serão feitos apontamentos em torno da política local brasileira, que tem se constituído em uma agenda de pesquisa ao longo das duas últimas décadas e que toma o processo de redemocratização, no início dos anos 1980, como ponto de partida (ROCHA E KERBAUY, 2014). Com a Constituição de 1988, o município foi elevado

\footnotetext{
${ }^{4}$ Alguns exemplos de produções recentes da Ciência Política nacional que fizeram uso da geografia eleitoral e da dimensão territorial podem ser vistos em Soares e Terron (2008), Meneguello e Bizzarro Neto (2012), Braga, Rodrigues-Silveira e Borges (2012) e Marzagão (2013).
} 
à categoria de ente federativo, tornando-se uma "entidade estatal, político-administrativa, com personalidade jurídica, governo próprio e competência normativa" (NEVES, 2000, p. 18). Além disso, as propostas descentralizadoras aprovadas na Constituinte causaram uma redefinição no arranjo estatal brasileiro, que passou de um modelo federalista de tipo centralizado para um modelo descentralizado e, em grande medida, cooperativo. No modelo centralizado, o governo federal possuía amplo grau de interferência tanto nos processos decisórios subnacionais quanto no controle de recursos. Já no modelo cooperativo, existem formas de ação conjuntas entre os níveis de governo, além de um substantivo nível de autonomia decisória e capacidade de autofinanciamento para os níveis estadual e municipal ${ }^{5}$.

No contexto democrático pós-1988, portanto, os municípios ganharam um novo papel e peso na política nacional. Os dados da Tabela 1 ilustram este cenário.

TABELA 1 - Número de Municípios, População e Taxa de Crescimento nos Censos Demográficos, segundo as Classes de Tamanho da População dos Municípios - 1960/2010

\begin{tabular}{|c|c|c|c|c|c|c|c|}
\hline \multirow{2}{*}{$\begin{array}{l}\text { Classes de tamanho da } \\
\text { população dos } \\
\text { municípios ( } \mathrm{n}^{\circ} \mathrm{de} \\
\text { habitantes) }\end{array}$} & \multicolumn{6}{|c|}{ Número de municípios e população nos Censos Demográficos } & \multirow{2}{*}{$\begin{array}{l}\text { Taxa de } \\
\text { crescimento } \\
\text { (Série } \\
\text { histórica) }\end{array}$} \\
\hline & $\begin{array}{l}01.09 .1960 \\
(1)\end{array}$ & \begin{tabular}{|l}
01.09 .1970 \\
$(1)$
\end{tabular} & $\begin{array}{l}01.09 .1980 \\
(1)\end{array}$ & $\begin{array}{l}01.09 .1991 \\
(2)\end{array}$ & $\begin{array}{l}01.08 .2000 \\
(2)\end{array}$ & $\begin{array}{l}01.08 .2010 \\
(2)\end{array}$ & \\
\hline \multicolumn{8}{|c|}{ Número de municípios } \\
\hline Total & 2766 & 3952 & 3991 & 4491 & $\mathbf{5 5 0 7}$ & 5565 & $101,10 \%$ \\
\hline $\begin{array}{l}\text { Até } 2000 \\
\text { De } 2001 \text { a }\end{array}$ & 15 & 56 & 56 & 58 & 105 & 118 & $686,7 \%$ \\
\hline $\begin{array}{c}5000 \\
\text { De } 5001 \mathrm{a}\end{array}$ & 263 & 602 & 610 & 682 & 1225 & 1183 & $349,8 \%$ \\
\hline $\begin{array}{c}10000 \\
\text { De } 10001 \text { a }\end{array}$ & 651 & 1058 & 957 & 1055 & 1312 & 1212 & $86,2 \%$ \\
\hline $\begin{array}{c}20000 \\
\text { De } 20001 \mathrm{a}\end{array}$ & 847 & 1159 & 1114 & 1299 & 1382 & 1401 & $65,4 \%$ \\
\hline $\begin{array}{c}50000 \\
\text { De } 50001 \mathrm{a}\end{array}$ & 783 & 826 & 872 & 926 & 958 & 1043 & $33,2 \%$ \\
\hline $\begin{array}{l}100000 \\
\text { Mais de }\end{array}$ & 143 & 157 & 240 & 284 & 301 & 325 & $127,3 \%$ \\
\hline $\begin{array}{c}100000 \\
\text { De } 100001 \mathrm{a}\end{array}$ & 64 & 94 & 142 & 187 & 224 & 283 & $342,2 \%$ \\
\hline $\begin{array}{l}500000 \\
\text { Mais de }\end{array}$ & 57 & 83 & 124 & 162 & 193 & 245 & $329,8 \%$ \\
\hline 500000 & 7 & 11 & 18 & 25 & 31 & 38 & $442,9 \%$ \\
\hline
\end{tabular}

Fonte: Inst. Bras. de Geografia e Estatística (IBGE), Censo Demográfico 1960, 1970, 1980, 1991, 2000 e 2010. (1) População recenseada. (2) População residente.

Desde 1960 até 2010, o número de municípios praticamente dobrou, registrando a maior taxa de crescimento dentre aquelas cidades com até 2000 habitantes $(686,7 \%)$. Na outra

\footnotetext{
${ }^{5}$ Para mais informações a respeito da discussão sobre os dois modelos, cf. Almeida (2005, pp. 30-32).
} 
ponta, as cidades com mais de 500.000 habitantes também registraram um crescimento acentuado $(442,9 \%)$. Este aumento no quantitativo traz uma série de novas responsabilidades, como: a transferência de recursos; a criação de cargos eletivos e para a máquina pública; a elaboração de políticas públicas; construção de estradas; criação de empregos, postos de saúde, hospitais, escolas, etc. A explosão no número de municípios traz, assim, desafios para a política nacional e, ao mesmo tempo, reconfigura os contextos locais e atribui-lhes novos contornos.

Nota-se, portanto, que ao falarmos de política local no Brasil, estamos nos referindo a realidades complexas e diversas, que atravessam cidades com volumes populacionais, demandas, características e contextos bastante distintos. Os dados da tabela 2, abaixo, reforçam este argumento: há municípios cuja porcentagem de domicílios rurais é significativa - destaque para aqueles até 20.000 habitantes, com cerca de $40 \%$ de suas populações vivendo na zona rural. No outro extremo, municípios com mais de 100.000 habitantes já registram mais de $94 \%$ de seus habitantes morando nos centros urbanos.

TABELA 2 - População residente, total e respectiva distribuição percentual por situação do domicílio, segundo as classes de tamanho da população dos municípios -2010

\begin{tabular}{|c|c|c|c|}
\hline \multirow{2}{*}{$\begin{array}{c}\text { Classes de tamanho da } \\
\text { população dos } \\
\text { municípios (n }{ }^{\circ} \text { de } \\
\text { habitantes) }\end{array}$} & \multirow{3}{|c|}{\begin{tabular}{c} 
População residente \\
\cline { 3 - 4 }
\end{tabular}} & Total & \multicolumn{2}{|c|}{ Distribuição percentual (\%) } \\
\cline { 3 - 4 } & & \multicolumn{2}{|c|}{ Situação do domicílio } \\
\cline { 3 - 4 } Total & $\mathbf{1 9 0 7 5 5 7 9 9}$ & Urbana & Rural \\
\hline Até 5 000 & 4374345 & $\mathbf{8 4 , 4}$ & $\mathbf{1 5 , 6}$ \\
\hline $\begin{array}{c}\text { De 5 001 até } \\
10000\end{array}$ & 8541935 & 56,3 \\
\hline $\begin{array}{c}\text { De 10 001 até } \\
20000\end{array}$ & 19743967 & 60,0 & 40,0 \\
\hline $\begin{array}{c}\text { De 20 001 até } \\
50000\end{array}$ & 31344671 & 60,9 & 39,2 \\
\hline $\begin{array}{c}\text { De 50 001 até } \\
100000\end{array}$ & 22314204 & 70,3 & 29,7 \\
\hline $\begin{array}{c}\text { De } 100001 \\
\text { até 500 000 }\end{array}$ & 48565171 & 81,0 & 19,0 \\
\hline $\begin{array}{c}\text { Mais de } \\
500000\end{array}$ & 55871506 & 94,5 & 5,5 \\
\hline
\end{tabular}

Fonte: IBGE, Censo Demográfico 2010.

É observando dados como estes que se pode dizer que o terreno da política local traz um quadro multifacetado e complexo, que tem impacto sobre a maneira de se fazer política. Dados como os de Braga e Pimentel Jr. (2013) demonstraram que as organizações partidárias se distribuem desigualmente pelo território brasileiro, e que a forma como os partidos estão 
estruturados possui relevância para os seus sucessos eleitorais. Já Avelar e Walter (2008) apontam para a transformação do mapa partidário no interior do país, também sujeito às desigualdades que configuram os municípios no Brasil.

Nesse sentido, ao olharmos para o poder local sob estes diferentes contornos, notamos que a política se faz, em grande medida, no nível regional (AGNEW, 2007). É este o argumento central que será defendido ao longo deste artigo, procurando levantar as perspectivas que surgem ao tratarmos da política municipal.

O texto está estruturado em três partes. Na primeira, a discussão teórica procura trazer diferentes abordagens em torno dos conceitos de contexto e lugar. Este pano de fundo teórico serve de base para a segunda sessão, que aponta alguns argumentos em torno da política local, para o caso brasileiro. Por fim, as conclusões fazem um balanço das considerações em torno do tema da política local.

\section{LUGAR E CONTEXTO: REVELANDO ESPECIFICIDADES DA POLÍTICA}

Ao abordar o tema da política local, torna-se fundamental compreendê-la a sob a ótica do conceito de lugar. Afinal, o exercício do poder político é feito a partir de um lugar, de um contexto (THERBORN, 2006). Segundo Agnew (2011), o conceito de lugar como categoria de análise tem sido resgatado pelas teorias recentes, sobretudo nos campos de estudo da geografia eleitoral. Recuperar as especificidades do lugar é um dos objetivos principais desse esforço, na tentativa de trazê-lo enquanto variável independente ${ }^{6} \mathrm{e}$, ao mesmo tempo, se contrapor à ideia de "homogeneização" dos lugares pelo Estado-nação, o que se desdobrou em uma noção genérica de território nacional (AGNEW, 2007).

Em estudo sobre a Itália na Segunda República, Agnew (2007) defende o argumento de que a política no país se estabelece em níveis regionais, e não nacionais. A tese da "nacionalização" da política italiana (a ideia de uma "Itália única"), na verdade, ocultaria uma série de dinâmicas locais que trazem diferentes padrões de interação político-partidária. Ainda que se refira apenas ao caso italiano, o estudo é um bom exemplo do exercício teórico que tem sido feito recentemente, para reforçar a importância de se entender o lugar em seus aspectos específicos, em contraposição a uma tendência nacional e homogeneizadora dos territórios. Trata-se, em última instância, de ressaltar a centralidade da região enquanto

\footnotetext{
${ }^{6} \mathrm{Ou}$ seja, o lugar enquanto um fator capaz de moldar a visão política dos atores e influenciar, consequentemente, os diferentes processos políticos (eleições, interações partidárias, relações intergovernamentais, etc).
} 
unidade de análise, questionando o tratamento dos países enquanto formas homogêneas (ANDERSEN E HEATH, 2003).

Wong (2006) e Scott (1999) corroboram com essa perspectiva, mas a partir da ideia do controle estatal perante os diferentes lugares sob sua jurisdição. Segundo os autores, na tarefa de delimitar os espaços para modelá-los e melhor controlá-los, o Estado perde as diversas informações que são geradas no cotidiano pelas pessoas, que constroem seus espaços e os preenchem com atividades diárias. Como resultado, o conhecimento local, que faz determinadas localidades funcionarem e sobreviverem, está para além do alcance dos representantes estatais - perdem-se, pois, as particularidades das regiões e suas dinâmicas próprias. Há, portanto, um gap entre as práticas locais e o conjunto de conhecimentos controlados pelo Estado, na medida em que este tende a homogeneizar tais práticas e a darlhes um contorno legível e de fácil entendimento.

Outro fator que contribuiria para essa padronização geográfica são os meios de comunicação, que segundo Canclini (2002), tendem a reproduzir a ordem social por meio da formação de uma noção de território que é restrita. Em se tratando especificamente das cidades, o autor destaca o papel de jornais, rádios e televisões na construção de uma imagem coletiva do espaço urbano que é padronizada. Essas mídias se concentram muito nos aspectos conhecidos da cidade, reforçando estereótipos e características comuns, em detrimento de uma expansão da visão sobre os ambientes urbanos e suas complexidades.

O contexto atual, de intensa globalização, disseminação da internet e de novas tecnologias que tem permeado os territórios convencionais da política e lhes adicionado novos itens (THRIFT, 2006), também tem trazido outro debate sobre o local. Agnew (2011) aponta para a existência de uma discussão em torno da ausência do lugar (placelessness). A presença dos não-lugares, como aeroportos, shopping centers e internet, tem crescido no cotidiano das sociedades contemporâneas, fazendo com que os sentidos do lugar fixo sejam perdidos em prol de uma vida no "lugar nenhum" (nowhere land). Entretanto, mesmo diante dessas transformações, o lugar não deixa de ser crucial para as relações sociais nos períodos atuais. Pelo contrário, são ainda os elementos centrais para a modelagem e apreensão dos processos políticos (AGNEW, 2011; 1996; THERBORN, 2006), bem como dos seus resultados (WONG, 2006).

Há três aspectos da vida social que, segundo Therborn (2006), são proporcionados pelo lugar. Primeiramente, o autor destaca que o lugar significa uma fixação no espaço: é um ponto estável no mapa e no tempo. Ou, desdobrando esta dimensão nos termos de Agnew (2011), trata-se de um ponto onde se tem um espaço particular, de vivência social e ocupação. 
O segundo elemento é o da contiguidade: o lugar é o palco para o encontro das pessoas, o estabelecimento de comunicações, relações sociais e vínculos (networks). Para Scheufele, Shanahan e Kim (2002), a constituição dessas redes sociais locais, a partir dos diferentes lugares pelos quais passam os cidadãos em suas vidas cotidianas, é fundamental para a criação de envolvimento político local. Nesse sentido, é a partir do lugar que se criam os incentivos para a própria agência dos indivíduos ${ }^{7}$, seja através do contato com as mídias locais ou da integração com a comunidade local, por exemplo (SCHEUFELE ET. AL., 2002). Para Therborn (2006), o lugar é capaz não apenas de sinalizar os significados dessa agência política, como também de afetar as suas consequências.

Por fim, o lugar traz um elemento de distinção, na medida em que uma determinada localidade é diferente da outra. O que definirá este lugar, em última instância, são as suas características, tanto espaciais e/ou territoriais como culturais, geradas a partir das práticas sociais e das relações estabelecidas. Ou seja, o lugar não é concebido como uma unidade natural, mas sim como algo construído a partir de suas interconexões com outros lugares. Suas fronteiras, portanto, são permeáveis e carregam em seu interior a diversidade, mais do que a homogeneidade, no que concerne aos seus atributos sociais e às experiências que ali ocorrem (AGNEW, 2011). Assim, entende-se que o lugar é melhor apreendido se colocado em termos relacionais.

Essa perspectiva de construção do local a partir de práticas sociais é, para Agnew (2011), uma ideia em comum compartilhada por quatro abordagens recentes sobre o lugar são elas: neo-marxista; humanista; feminista e performativa ${ }^{8}$. Há, também, uma crítica em comum a todas elas: a falta de uma base empírica para se trabalhar a questão do lugar. Procurando preencher esta lacuna e trazer os conceitos para propósitos mais empíricos, o autor também coloca uma definição do lugar em três eixos, que dialogam diretamente com a perspectiva de Therborn (2006) caracterizada acima.

A primeira dimensão é a do lugar enquanto localização de uma atividade ou objeto, que por sua vez estão relacionados a outras localidades por conta das interações, movimentações e difusões existentes entre elas. A segunda dimensão é a cotidiana, ou seja, o lugar como uma série de locais onde as atividades diárias e as transformações ambientais acontecem (casas, locais de trabalho, shopping centers, igrejas, etc.). Tais locais contribuem

\footnotetext{
7 A dimensão do local enquanto fator primordial para a participação é explorada mais a fundo por Pateman (1992), em sua defesa da democracia participativa. Para a autora, a partir da participação em nível local, é possível disseminar melhor os valores democráticos pela sociedade, devido à proximidade do cidadão com as suas demandas locais. O estímulo a essa participação, segundo Castells e Borja (1996), cabe aos governos locais.

${ }^{8}$ Para mais detalhes sobre cada uma das abordagens, cf. Agnew (2011, pp. 17-22).
} 
para a conformação de valores, atitudes e comportamentos entre os indivíduos - ou, na chave conceitual trabalhada por Scheufele, Shanahan e Kim (2002), esses locais cotidianos possibilitam a formação de laços sócio-estruturais dos indivíduos com a comunidade. Por fim, tem-se a dimensão do lugar como um sentido de identificação e pertencimento: o lugar enquanto uma comunidade única, dotada de uma moral e um ambiente próprios. Esse "sentido do lugar”, para Agnew, é um pré-requisito necessário para a solidariedade social e a ação coletiva.

Therborn (2006) também traz essa perspectiva subjetiva do local, enquanto um produtor de sentido para os agentes. Porém, Thrift (2006) dá um passo além e problematiza a dimensão do afeto e da subjetividade enquanto mecanismos utilizados para os processos políticos. Os lugares são dotados de uma simbologia, capaz de moldar as atividades humanas, suas interações e escolhas políticas. Nesse sentido, a construção das preferências é resultante da maneira como os indivíduos lidam com os lugares pelos quais habitam e passam. Thrift (2006) destaca três dimensões nas quais o afeto é mobilizado para os processos políticos.

A primeira dimensão é a da atenção, que se refere à conquista da população a partir dos seus interesses e demandas, procurando transformar a realidade em textos narrativos atrativos. Constrói-se um imaginário que é capaz de delimitar as ações e espaços dos indivíduos, dentro daquilo que lhes são de particular interesse. Já a dimensão da democracia contemporânea está relacionada à mobilização de sentimentos para que os cidadãos optem por determinadas escolhas políticas. São formulados argumentos e mecanismos capazes de convencer estes cidadãos a agir de determinadas formas. Nesse processo mobilizador, utilizase muito o discurso de inclusão de parcelas geralmente excluídas do jogo político, como uma forma de ampliar as bases de apoio a certos projetos. Em terceiro lugar, lança-se mão da dimensão da esperança: olhar para o futuro, construir aspirações políticas e prospecções são as principais ações feitas nesse sentido.

A partir dessas dimensões, os lugares podem definir as pautas políticas a serem abordadas. Dependendo dos contextos, essas pautas podem variar. As mídias, aqui, tem um papel importante (SCHEUFELE et. al., 2002), na medida em que são agentes construtores de seus contextos (CANCLINI, 2002). Portanto, ao colocar o lugar em primeiro plano, nota-se que a formação do imaginário político sofre influência das dinâmicas e características dos contextos específicos em que estão inseridos, permeados por interesses e disputas que mobilizarão, de diferentes modos, a dimensão afetiva dos cidadãos (THRIFT, 2006).

Diante dessas considerações, o argumento geral a ser destacado é o de que o contexto é um elemento central para se compreender os processos políticos, a agência dos indivíduos e 
a formação de suas preferências. O comportamento político é mais precisamente analisado se levarmos em conta que os diferentes processos de associação dos partidos com os lugares não são simplesmente homogeneizados pelos territórios, nem tampouco dependentes apenas do comportamento individual. Pelo contrário, Agnew (2007) defende a existência de uma dimensão intermediária, que é o contexto político e social: locais de trabalho, residência, origem e organização partidária, práticas religiosas, associações, acontecimentos históricos, conflitos sociais, tomadas de decisão eleitoral, etc. Trata-se de reconhecer que a política não é feita sem território: os partidos recebem diferentes formas e quantidades de apoios políticos, a depender das redes sociais criadas, dos processos de socialização e da atuação dos indivíduos ao longo dos lugares geográficos em que estão presentes (SOARES; TERRON, 2008; BRAGA, RODRIGUES-SILVEIRA E BORGES, 2012; MARZAGÃO, 2013). Nas palavras do próprio Agnew (2002, p. 21),

\footnotetext{
Places are the cultural settings where localized and geographically wideranging socioeconomic processes that condition actions of one sort or another are jointly mediated. Although there must be places, therefore, there need not be this particular place.
}

Portanto, o contexto é um elemento mediador entre a política nacional e a política local, na medida em que cria os processos socioeconômicos que condicionam as ações dos atores e a construção de suas identidades (ANDERSEN E HEATH, 2003). Não há causas singulares e universais para a ação política, mas sim fatores sociais multiescalares que a influenciarão de acordo com os contextos (AGNEW, 1996). Nesse sentido, as informações são recebidas e interpretadas pelos indivíduos de maneiras distintas ao longo dos lugares, levando a diferentes maneiras de se conceber os processos políticos e as dinâmicas sociais. Inclusive em se tratando de comunicação midiática, cujo papel "nacionalizante" da política pela televisão é questionado por Agnew (2007), cabe destacar que ela tem "significados e repercussões diferentes em grupos de distinta localização econômica e sócio-cultural" (CANCLINI, 2002, p. 49). Ou seja, a comunicação midiática - sobretudo jornais, rádios e televisões - fornecem um bom exemplo de como são apreendidos os processos cotidianos pelos indivíduos, dependendo de fatores contextuais ligados à economia, às práticas culturais, à localização geográfica etc. Isso faz com que a própria agência seja ressignificada pelo local (SCHEUFELE et. al., 2002).

Em termos de processos político-partidários, a dimensão contextual trabalhada por Agnew (2007) mostra que os níveis de apoio às coalizões partidárias variam significativamente entre as regiões. Não cabe, portanto, a ideia de um apoio uniforme, 
geograficamente, aos partidos políticos. As disputas eleitorais se dão em diferentes configurações sociais, econômicas e culturais, fazendo com que as atitudes políticas e a escolha do voto se deem a partir de identidades sociais formadas distintamente (ANDERSEN E HEATH, 2003). Nesse sentido, é importante não apenas o sucesso eleitoral, mas de onde vem os votos - ou em outros termos, onde estão localizadas as bases eleitorais dos partidos e quais são as suas características. O lugar, portanto, é um centro irradiador de poder, tornandose um palco importante para a montagem de estratégias eleitorais (THERBORN, 2006).

Esse debate em torno dos contextos políticos e da formação de bases políticopartidárias nos direciona para o tema da política local. Compreender os fenômenos políticos locais a partir dos diferentes contextos permite apreender realidades sociais distintas, que seriam ocultadas em um enfoque nacional da política. A chave de análise contextual não nos leva, por outro lado, a um relativismo sem fim ou a um apelo puramente regionalista. $\mathrm{O}$ esforço teórico a ser feito é o de justamente conectar a abordagem contextual da política local (AGNEW, 2011; 2002) à sua dimensão nacional, de modo a esclarecer suas interconexões e influências ${ }^{9}$. À luz dessa linha argumentativa, pretende-se, na próxima sessão, discutir alguns pontos da política local, a partir o caso brasileiro, com enfoque na dimensão partidária e eleitoral.

\section{A POLÍTICA LOCAL E OS MUNICÍPIOS BRASILEIROS}

Os estudos sobre política local se referem às análises das unidades sub-estatais. Mais especificamente, trata-se de colocar o poder municipal em primeiro plano, nas suas mais diversas dimensões. Trounstine (2009) e Judd (2005) em um panorama sobre os estudos de política local nos Estados Unidos, identificaram uma marginalização do tema na Ciência Política e nos estudos urbanos. Isso estaria relacionado, segundo Trounstine, a três fatores.

Em primeiro lugar, há uma falha dos pesquisadores em conectar suas questões e achados sobre política local com fenômenos mais amplos da Ciência Política, levando à criação de muitos "particularismos" analíticos e com pouco alcance teórico. Um segundo problema é de caráter metodológico, por conta do excesso de normatividade e intolerância ideológica por parte dos estudiosos, associados à adaptação inadequada de outras técnicas mais generalizantes e quantitativas. Segundo a autora, os pesquisadores focaram muito em

\footnotetext{
${ }^{9}$ Por exemplo, o terceiro ponto definidor do lugar trazido por Agnew (2011) - enquanto um sentido simbólico de identificação e pertencimento - nos permite pensar a legitimidade dos Estados e a criação de identidades nacionais.
} 
métodos qualitativos direcionados a solucionar apenas casos específicos, sem criar metodologias que pudessem ser replicadas a outras pesquisas. Por fim, as cidades não são tidas como importantes para a vida política. As atenções e análises se voltam para os quadros nacionais e, no máximo, estaduais.

Para o caso brasileiro, os desafios apontados nos dois primeiros fatores por Trounstine (2009) são os mesmos: fugir dos particularismos e, concomitantemente, propor metodologias que permitam um diálogo mais amplo com outros objetos e enfoques. Sobre o lugar secundário ocupado pela política local, em favor dos estudos sobre o ambiente nacional, Dantas (2014) identifica o mesmo problema. Tanto em termos de cobertura midiática quanto de enfoques de pesquisa, o autor argumenta que a política nacional ganha destaque, na tentativa de se produzir conhecimentos mais gerais sobre o país. No entanto, muito se perde nessa abordagem, na medida em que se segue desconhecendo mais a fundo as realidades regionais e suas particularidades. Não se trata, porém, de ignorar a política nacional, mas sim de "aprimorarmos a capacidade de enxergarmos o local, visando à compreensão do todo e suas distinções" (DANTAS, 2014, p. 6).

Trounstine (2009, pp. 613-615) traz três justificativas que defendem a importância de se estudar a política local, nos Estados Unidos. Especificamente, o primeiro deles merece destaque aqui ${ }^{10}$. A autora argumenta que os contextos locais moldam a política nos âmbitos estadual e nacional, ou seja, a atividade política acontece, em grande medida, no nível subnacional. Em que pesem as diferenças nas competências dos municípios norte-americanos em relação aos brasileiros, pode-se dizer que os municípios brasileiros adquiriram grande peso tanto na administração pública quanto nas tomadas de decisão, sobretudo após a Constituição de 1988.

O aumento do poder dos municípios no Brasil é fruto do processo de descentralização ${ }^{11}$ da estrutura estatal administrativa, que teve início no ambiente de abertura política (anos 1980) e representou uma mudança significativa no padrão de relação até então existente entre os níveis de governo. De acordo com Samuels (2000), a trajetória política brasileira demonstra que os municípios foram, historicamente, altamente dependentes dos

\footnotetext{
${ }^{10}$ Os outros dois argumentos se referem a questões metodológicas e a produção de teorias mais gerais acerca do nível local.

${ }^{11}$ A descentralização se refere à "transferência de autoridade e responsabilidade, no que diz respeito a funções públicas, do governo central para governos locais ou intermediários, para organizações governamentais semiindependentes e/ou para o setor privado" (WORLD BANK, 2002 apud. ALMEIDA, 2005, p. 30). Cabe destacar que a descentralização não pressupõe, necessariamente, uma redução da importância do governo nacional (ALMEIDA, 2005). Para maiores desdobramentos sobre o tema, consultar: Arretche (1999), Samuels (2000; 2004), Almeida e Carneiro (2003) e Almeida (2005).
} 
governos centrais, possuindo baixa autonomia tanto em termos de gestão administrativa quanto de tomadas de decisões. Convivendo com essa falta de autonomia legal, os líderes municipais governistas gozavam de ampla autonomia extralegal concedida pelos governos estaduais como parte de suas funções no acordo típico do coronelismo ${ }^{12}$ (LEAL, 2012 [1948]).

Carvalho (1968; 1979) também corrobora com esta visão, argumentando que, durante o século XIX e início do século XX, o poder local abrigava sistemas autônomos que progrediam sem se articular fortemente com os corpos políticos de nível regional e nacional. Outros autores que apresentam perspectiva semelhante de análise são Queiroz (1976) e Cintra (1971; 1974), ao defenderem que, no lugar de uma fachada de integração e institucionalização política em nível nacional, na verdade o que ocorria no Brasil era a permanência de um poder disperso e atomizado em nível local. Nesse sentido, prevalecia no limite um sistema de poder familiar, local e baseado em relações clientelistas.

Schwartzman (2015 [1982], p. 174) vai contra esta abordagem, colocando que "o problema teórico dessa visão das coisas é que ela tende a considerar a estrutura política nacional como algo praticamente insignificante". O autor prossegue em sua crítica, afirmando que o que ocorria no Brasil, sobretudo durante o Império era, ao mesmo tempo, tanto o processo de centralização política - por meio de uma monarquia centralizada, hierárquica e baseada em sua própria máquina administrativa para subsistir - quanto de descentralização através de um poder privado difuso e autônomo, "que só adquiria expressão política quando era cooptado pelo Estado [...]” (SCHWARTZMAN, 2015, p. 174).

Tal contraposição entre o local e o nacional, que adquiriu diversos significados na literatura (QUEIROZ, 1976; CARVALHO, 1979; LEAL, 2012; SCHWARTZMAN, 2015) teve vigência significativa até meados do século XX. A partir dos anos 1950, o âmbito local passou a sofrer diversas transformações, especialmente após o regime militar. Kerbauy (2000) destaca, principalmente, as mudanças de caráter institucional ${ }^{13}$, que foram responsáveis por redefinir o perfil do poder local. A isso, somam-se os processos de intensa urbanização e de crescimento populacional (SAMUELS, 2000). É justamente dos efeitos das mudanças institucionais sobre essas transformações urbanas que, segundo Kerbauy (2000), criaram-se as

\footnotetext{
${ }^{12}$ Nas palavras de Leal (2012), o coronelismo "é sobretudo um compromisso, uma troca de proveitos entre o poder público, progressivamente fortalecido, e a decadente influência social dos chefes locais, notadamente dos senhores de terras" (p. 44). Uma revisão sobre este conceito, em comparação com os de "mandonismo" e "clientelismo" é feita em Carvalho (1997).

13 As principais mudanças institucionais foram: a extinção dos antigos partidos políticos e a implantação do bipartidarismo (1965); a reforma tributária (1965); a Lei Orgânica dos Municípios (1967); e a restrição do papel do Legislativo (1967) (KERBAUY, 2000, p. 14).
} 
condições políticas propícias ao desaparecimento do coronelismo e ao surgimento de novas características na política local. O poder público passa a existir em locais até então isolados politicamente, que proviam grande autonomia e exclusividade aos núcleos privados, tanto na administração local quanto na mediação com os demais níveis de governo. Aliado a isso, a crescente população urbana trouxe diferentes necessidades e demandas, em relação à população rural até então predominante. Surgem, portanto, formas de participação mais efetivas do eleitorado, novas configurações nas relações entre os três níveis de governo e novos tipos de relações políticas, menos integradas às máquinas clientelistas tradicionais (SAMUELS, 2000) e mais alinhadas aos componentes nacionais - ainda que, nos micro e pequenos municípios, permaneçam alguns graus de dominância local (SANTOS, 2013).

Como observam Almeida e Carneiro (2003, p. 130), "na volta à democracia, o país contava, em dimensão impossível de precisar, com lideranças locais formadas no jogo eleitoral e, frequentemente, com alguma experiência de gestão de programas sociais”. Essas experiências e trajetórias políticas foram importantes para as articulações em torno do tema da descentralização, no contexto da Constituinte. Nesse sentido, desde os anos 1980, temos assistido no país um aumento na articulação do nível local com o nacional, seja em sentido ascendente ou descendente (CARNEIRO E ALMEIDA, 2008; SANTOS, 2013). Isso tem se dado tanto na dimensão eleitoral quanto da elaboração de políticas públicas.

Samuels (2000) demonstra que, neste contexto de abertura política e de aumento nas prerrogativas do nível local, os políticos optaram por solidificar suas bases nos municípios, em vez de retornarem ao status pré-1964 que conferia maiores poderes e status aos cargos estaduais e nacionais. Para o autor, isso se deve à concentração de poder existente em nível local e, em particular, nas prefeituras a partir de então: controle sobre o orçamento, responsabilidade sobre contratações e demissões; capacidade de implementar obras públicas; execução de diversas políticas públicas; etc. Este conjunto de competências faz com que o cargo de prefeito confira uma visibilidade importante aos políticos. A contraposição, aqui, é feita principalmente com relação ao cargo de deputado federal: Samuels (1998) mostra que, comparativamente, os deputados federais têm menos acessos aos recursos públicos do que os prefeitos - o que gera um aumento no interesse desses políticos pelo nível municipal. O argumento do autor vai ainda mais longe, defendendo que, no contexto pós-1988, a política nacional e estadual é que se torna uma espécie de "passagem" para a política municipal (SAMUELS, 2000).

De fato, como apontam Vasquez (2016) e Peixoto e Goulart (2014), as eleições municipais para o Executivo tem sido cada vez mais disputadas, resultando em elevação no 
grau de competitividade. Para Barone (2010), tal crescimento da competição gera não apenas o aumento nas disputas entre partidos e lideranças, mas também nas máquinas públicas, pois “onde houve maior competição política, maior foi a expansão do emprego público municipal após a eleição" (BARONE, 2010, p. 34). Afinal, o controle dos recursos disponíveis nas prefeituras é um dos principais instrumentos políticos que os prefeitos utilizam no atendimento das demandas e dos interesses de seus apoiadores. O autor também indica que há uma significativa elevação no número de empregados públicos nas prefeituras, ao longo dos anos $2000^{14}$. Além disso, o aumento na procura e no sucesso da reeleição por parte desses prefeitos eleitos (incumbents ${ }^{15}$ ), como identifica Barreto (2012), também se torna um indicador da importância que os pleitos locais têm no sistema político brasileiro - sobretudo dos pontos de vista do controle, pelas elites, do orçamento, da gestão pública e das estratégias político-partidárias (como será apontado mais adiante).

Quando se trata da apreensão de valores e ideologias por essas elites locais, Almeida e Carneiro (2003) apontam que há entendimento, por parte delas, acerca da democracia e seus componentes. Os autores demonstram que a postura majoritariamente favorável ao regime democrático é alta, superando os $90 \%$, dentre os entrevistados no survey ${ }^{16}$, e que a relação dessas elites com os partidos políticos é forte - sobretudo entre o grupo detentor de cargos governamentais. Nesse sentido, pode-se observar que os partidos estão presentes no nível local e são referenciais importantes para a atividade das elites dirigentes.

Sobre as atuações partidárias, o contexto local também se revela como um locus central para o desenvolvimento da coordenação e estratégia políticas. Barone (2010) demonstra que a administração pública e o funcionalismo municipal sofrem variações em seus formatos, a depender do partido que governa a Prefeitura. Já Carneiro e Almeida (2008) destacam a importância dos sistemas partidários em nível municipal, defendendo que há conexão entre os diferentes níveis de governos e o sistema de partidos - sobretudo a partir de suas bases municipais. As análises dos autores demonstram que essa coordenação política pelos partidos e lideranças ocorre nos diferentes níveis e nas diversas competições eleitorais. Nesses processos, a criação e a manutenção da reputação partidária se tornam desafios centrais para as lideranças locais, que precisam controlar as iniciativas individuais que possam gerar algum conflito com as posições programáticas da legenda. Em outras palavras, a

14 Entre 2004 e 2008, houve um aumento de quase $18 \%$ no número de funcionários empregados na administração (direta e indireta) dos municípios (BARONE, 2010, p. 12).

${ }^{15}$ De modo sintético, o incumbent é o prefeito eleito que, no pleito seguinte, disputa novamente o mesmo cargo.

${ }^{16}$ Para os dados completos, cf. Almeida e Carneiro, 2003, p. 134. 
política local guarda suas especificidades, mas não está totalmente isolada e distorcida da política regional ou nacional. Este desafio de articulação colocado aos partidos e lideranças pelo contexto local se resume da seguinte maneira:

\begin{abstract}
O município é uma arena de disputa eleitoral e de decisões de governo com perfil, instrumentos e recursos específicos. Quando se trata de formar o governo municipal, as escolhas dos eleitores podem ser feitas considerando apenas suas consequências prováveis no âmbito local. Políticos podem traçar estratégias de disputa por votos sem se preocupar com o que ocorre nas outras esferas da Federação; os partidos, na busca de êxito em pleitos municipais, têm de adaptar objetivos de escopo mais amplo às peculiaridades da competição em cada município (CARNEIRO E ALMEIDA, 2008, p. 407).
\end{abstract}

Este esforço de coordenação feito pelos partidos acontece, segundo Carneiro e Almeida (2008), na medida em que há articulação da competição por votos nas três esferas de governo.

Outra maneira de observar a centralidade da política local para as coordenações partidárias vai no sentido contrário - da montagem de estratégias dos pleitos nacionais em direção às bases locais. Davidian, Silva e Mesquita (2012) afirmam que há estratégias plurais para que os partidos obtenham mais participação na Câmara dos Deputados. Uma delas é a escolha da lista partidária que será oferecida aos eleitores. A outra estratégia é a da regionalização do voto, ou seja, aumentar a abrangência regional do partido, com candidatos que façam campanhas em áreas distintas. Assim, a legenda conseguiria atrair um número maior de eleitores e, consequentemente, expandir a participação na Câmara Federal. A principal conclusão dos autores é a de que, nos pleitos proporcionais nacionais, a dimensão regional é fundamental para se compreender as estratégias de fortalecimento partidário na Câmara. Uma delas é a dispersão dos votos pelo território. Ou seja, o aspecto local faz diferença para a maneira como as agremiações atuarão nas disputas ${ }^{17}$.

Nota-se, diante desses apontamentos, que o município e a política local não estão isolados, obedecendo a uma lógica particularista da política que desconsidera os demais níveis de governo e as dinâmicas político-partidárias estaduais e federais. A coordenação do sistema partidário brasileiro em três níveis, elucidada por Carneiro e Almeida (2008), mostra que as bases locais são fundamentais para se compreender as disputas políticas, bem como o comportamento do eleitorado e das lideranças partidárias.

Porém, ainda que a política local abra espaço para mecanismos de autonomia e ação partidária, não se pode deixar de considerar que há muitos desafios a serem vencidos nas

\footnotetext{
17 Em Marzagão (2013) e Speck e Cervi (2016), também há a defesa do contexto local enquanto variável importante para se explicar a dispersão e os padrões de votação.
} 
cidades, em termos de democratização, aumento da eficiência do poder local e dos mecanismos de representação. Por exemplo, o continuísmo das elites tradicionais e suas práticas após a redemocratização (HAGOPIAN, 1996) parece se refletir também no nível local. Ainda que o aumento na competição municipal tenha contribuído para diminuir padrões clientelistas no fazer político (KERBAUY, 2000; SANTOS, 2013), a dominância do Executivo municipal abre espaço também para o desenvolvimento de mecanismos políticos individualistas, nos moldes clientelistas. Os prefeitos podem continuar atuando como "chefes locais", o que compromete a cooperação intergovernamental (SAMUELS, 2000).

Outra dificuldade que se impõe é a do exercício, de fato, da autonomia pelos municípios. Essa capacidade sofreu restrições a partir dos anos 1990, sobretudo nos âmbitos fiscal e social, cujos objetivos eram promover a disciplina fiscal em todos os níveis de governo e garantir regularidade e estabilidade no uso dos recursos destinados aos programas sociais (ALMEIDA, 2005). Assim, os impulsos centralizadores e descentralizadores a que estão submetidas as relações intergovernamentais colocam desafios à coordenação política das três esferas de governo, e podem restringir o poder de atuação dos municípios.

$\mathrm{O}$ argumento acerca dessa restrição é reforçado pelos dados de Almeida e Carneiro (2003), ao apontarem que os governos municipais, na percepção das elites entrevistadas, ainda permanecem subordinados ao governo federal no que tange aos problemas locais mais urgentes - como pobreza, desemprego e educação. Por outro lado, os resultados revelam resistências à descentralização de atribuições e competências em várias áreas importantes, entre as lideranças locais. Ou seja, a existência de uma tendência a valorizar as funções do governo municipal, trazida pela descentralização, não garante ainda uma aceitação ampla de responsabilidades. Os dados demonstram, ainda, que discussões importantes sobre direitos civis ainda não encontram bases e ambientes consistentes entre essas elites.

Por fim, cabe chamar a atenção para os problemas relacionados à distribuição desigual dos recursos públicos entre as diferentes localidades. Abrucio e Couto (1996) argumentam que as condições da descentralização não são as mesmas entre as regiões brasileiras, visto que há distorções na redistribuição dos recursos, causadas pela legislação. A ausência de mecanismos institucionais que tornem a descentralização mais equitativa também é uma dificuldade à autonomia de alguns municípios, sobretudo daqueles localizados nos estados mais pobres.

A partir de outra abordagem, Speck e Cervi (2016) defendem o mesmo argumento: as desigualdades regionais geram formas diferentes de se praticar (e entender) a política pelo território nacional. Os autores identificam que a competição eleitoral apresenta diferentes 
padrões, ao considerarmos os portes dos municípios: "as condições de disputa em municípios pequenos são distintas das de municípios grandes e, quando se pretende explicar o desempenho eleitoral dos candidatos, isso deve ser levado em consideração" (SPECK E CERVI, 2016, p. 82). Ou seja, as particularidades geradas pelos municípios brasileiros são fundamentais para compreendermos as dinâmicas políticas locais. Portanto, a igualdade de status legal entre os municípios oculta uma desigualdade real e regional marcantes, tanto do ponto de vista político quanto socioeconômico.

Diante deste breve quadro, podem-se destacar três eixos que evidenciam alguns dos desafios existentes aos municípios e seus papéis perante a federação: a cooperação intergovernamental, buscando clarear as responsabilidades de cada nível de governo (SAMUELS, 2000; ALMEIDA E CARNEIRO, 2003); a igualdade real de condições para o exercício da autonomia entre todos os municípios, visando principalmente à eliminação das desigualdades a que estão submetidos os municípios menos assistidos; e o fortalecimento dos mecanismos de representação, participação e gestão, buscando formas inovadoras do fazer político e de atuação dos partidos e lideranças, em consonância tanto com as demandas locais quanto com as dinâmicas político-partidárias das demais esferas de governo.

Nota-se, então, que o olhar sobre o poder local atribui maior importância ao contexto onde estão se desenvolvendo os fenômenos políticos. Porém, para o caso brasileiro, este ganho analítico não está isento de desafios, principalmente no que concerne a mudanças em normas legais e práticas tradicionais do fazer político. A relação da política local com a nacional revela que há coordenação entre os níveis de governo mas que, ao mesmo tempo, há muito a ser descoberto sobre os processos políticos regionais e suas formas de implantação.

\section{CONCLUSÕES}

A política local revela um ambiente sujeito a diversos desafios, tanto práticos quanto teórico-metodológicos. Todavia, ao levarmos em conta a dimensão analítica do contexto, temos a possibilidade de compreender melhor os acontecimentos políticos e sociais que se desenvolvem nos municípios e regiões, revelando aspectos que ficariam ocultos em enfoques empíricos nacionais. Não se trata, no entanto, de particularizar os fenômenos e relativizá-los: o esforço a ser feito é o de justamente evidenciar as coordenações e conexões existentes entre as três esferas de governo e, em que medida, elas estão se influenciando e interagindo.

Para o caso brasileiro, o novo status legal conferido às cidades no pós-1988 trouxe um novo olhar para o poder local, que já vinha passando por mudanças desde a segunda 
metade do século XX. De modo geral, tem ocorrido uma ampliação das agendas de pesquisas sobre política local (ROCHA E KERBAUY, 2014) e que levam em consideração a dimensão do contexto e do território (TERRON, 2012; MARZAGÃO, 2013).

Por fim, cabe ressaltar que as mudanças e as dinâmicas no nível local apontadas pela literatura brasileira permitem pensar novas formas e desafios para a representação política. No contexto democrático atual, essa representatividade se dá de diferentes formas, procurando incluir grupos não representados formalmente e instaurar formas não institucionais de participação (MANIN, 2012). Nota-se, pois, que a ideia de representação e participação vai muito além da esfera partidária (MANIN, 2012) e coloca novos estímulos às instituições formais representativas. O ambiente local nos permite observar mudanças estruturais da política (MANIN, 1998) que já vem ocorrendo há algumas décadas no país (KERBAUY, 2000; SANTOS, 2013). Essas transformações afetam não só a atuação partidária (AVELAR E WALTER, 2008), mas também as práticas cotidianas dos cidadãos, em termos de participação, de interações sociais, de demandas e da formação de preferências políticas.

\section{REFERÊNCIAS BIBLIOGRÁFICAS:}

ABRUCIO, F.; COUTO, C. 1996. A Redefinição do Papel do Estado no Âmbito Local. São Paulo em Perspectiva, vol. 10, n. 3, pp. 40-47.

AGNEW, J. 1996. Mapping politics: how context counts in electoral geography. Political Geography, vol. 5, n. 2, pp. 129-146.

2002. Place and Politics in Modern Italy. Chicago: University of Chicago Press.

2007. Remaking Italy? Place Configurations and Italian Electoral Politics Under the "Second Republic". Modern Italy, vol. 12, n. 1.

2011. Space and Place. In: AGNEW, J.; LIVINGSTONE, D. (eds). Handbook of Geographical Knowledge. London: Sage.

ALMEIDA, M. H. T.; CARNEIRO, L. P. 2003. Liderança local, democracia e políticas públicas no Brasil. Opinião Pública, vol. 9, n. 1, pp. 124-147.

2005. Recentralizando a Federação? Revista de Sociologia e Política, vol. 24, pp.

$29-40$.

ANDERSEN, R.; HEATH, A. 2003. Social identities and political cleavages: the role of political context. J. R. Statistic Soc. A, pp. 301-327.

ARRETCHE, M. Políticas sociais no Brasil: descentralização em um Estado federativo. Revista Brasileira de Ciências Sociais, vol. 14, n 40, p. 111-141, 1999. 
AVELAR, L.; WALTER, M. I. M. 2008. Lentas mudanças: o voto e a política tradicional. Opinião Pública, vol. 14, n. 1, pp. 96-122.

BARONE, L. S. Emprego público e política: uma radiografia da gestão 2005/2008 nos municípios brasileiros. III Congresso Consad de Gestão Pública, 2010. Disponível em: http://www.escoladegestao.pr.gov.br/arquivos/File/Material_\%20CONSAD/paineis_III_congr esso_consad/painel_3/emprego_publico_e_politica_.pdf. Acessado em: 25/04/17.

BARRETO, A. A. B. Eleições municipais comparadas: a escolha do chefe do Executivo no Brasil e no Uruguai e os impactos sobre os sistemas partidários locais. Revista Brasileira de Ciência Política, n. 7, pp. 285-318, 2012.

BRAGA, M. S. S.; RODRIGUES-SILVEIRA, R.; BORGES, T. 2012. Organización, território y sistema partidário: difusión territorial de la organización de los partidos y sus potenciales impactos sobre la estrutura del sistema partidário em Brasil. América Latina Hoy, vol. 62 , pp. 15-45.

; PIMENTEL JR., J. 2013. Estrutura e organização partidária municipal nas eleições de 2012. Cadernos Adenauer XIV, n. 2.

CANCLINI, N. 2002. Cidades e cidadãos imaginados pelos meios de comunicação. Opinião Pública, vol. 8, n. 1, pp. 40-53

CARNEIRO, L. P.; ALMEIDA, M. H. T. 2008 Definindo a Arena Política Local: Sistemas Partidários Municipais na Federação Brasileira. DADOS, vol. 51, n. 2, pp. 403-432.

CARVAlHO, J. M.. Mandonismo, Coronelismo, Clientelismo: Uma discussão conceitual. DADOS - Revista de Ciências Sociais, vol. 40, n. 2, 1997.

CASTELLS, M.; BORJA, J. 1996. As cidades como atores políticos. Novos Estudos CEBRAP, no 45 , pp. 152-166.

CINTRA, A. O. A integração do processo político no Brasil: algumas hipóteses inspiradas na literatura. Revista de Administração Pública, vol. 5, n. 2, 1971.

A política tradicional brasileira: uma interpretação das relações entre o centro e a periferia. Cadernos do Departamento de Ciência Política, vol. 1, 1974.

CORRÊA, R. L. 2008. A rede urbana. São Paulo: Editora Ática.

DANTAS, H. 2014. Prefácio: $O$ desafio de compreender a política municipal. In: ROCHA, M. M.; KERBAUY, M. T. M. (orgs). Eleições, partidos e representação política nos municípios brasileiros. Juiz de Fora: Editora UFJF.

DAVIDIAN, A.; SILVA, G.; MESQUITA, L. 2012. A regionalização dos votos partidários para Câmara Federal no Rio de Janeiro nas eleições de 2010. Em Debate, v. 4,n. 2,pp. 4352. 
HAGOPIAN, F. 1996. Traditional politics and regime change in Brazil. Cambridge; New York: Cambridge University Press.

JUDD, D. 2005. Everything is always going to hell: Urban scholars as end-times prophets. Urban Affairs Review, vol. 41, n. 2, pp. 119-131.

KERBAUY, M. T. M. 2000. A morte dos coronéis: política interiorana e poder local. Araraquara/SP: FCL/Laboratório Editorial/UNESP.

LEAL, V. N. 2012. Coronelismo, Enxada e Voto: $O$ município e o regime representativo no Brasil. São Paulo: Companhia das Letras.

MANIN, B. 1998. Los Principios del Gobierno Representativo. Madrid: Alianza Editorial. 2012. A democracia do público reconsiderada. Novos Estudos, n. 97, pp. 115-127.

MARZAGÃO, T. A dimensão geográfica das eleições brasileiras. Opinião Pública, vol. 19, n. 2, pp. 270-290, 2013.

MENEGUELlO, R.; BIZZARRO NETO, F. 2012. Contexto e Competição na Política Paulista. DADOS - Revista de Ciências Sociais, vol. 55, n. 1.

NEVES, G. H. 2000. O município no Brasil: Marco de referência e principais desafios. In: NEVES et. al. Os municípios e as eleições de 2000. Cadernos Adenauer 4. São Paulo: Fundação Konrad-Adenauer Stiftung.

PATEMAN, C. 1992. Participação e Teoria Democrática. Rio de Janeiro: Paz e Terra.

PEIXOTO, V. M.; GOULART, N. L. M. Evolução da competição eleitoral municipal no Brasil (1996-2012). Teoria e Pesquisa, vol. 23, n. 2, pp. 41-63, 2014.

ROCHA, M. M.; KERBAUY, M. T. M. 2014. Poder local e representação política nos municípios brasileiros: contribuições para uma agenda de pesquisas. In: ROCHA, M. M.; KERBAUY, M. T. M. (orgs). Eleições, partidos e representação política nos municípios brasileiros. Juiz de Fora: Editora UFJF.

QUEIROZ, M. I. P. O mandonismo local na vida política brasileira. São Paulo: Alfa-Ômega, 1976.

SAMUELS, D. 1998. Careerism and Its Consequences: Federalism, Elections, and PolicyMaking in Brazil. San Diego: University of California.

2000. Reiventing Local Government? Municipalities and Intergovernmental Relations in Democratic Brazil. In: POWER, T.; KINGSTONE, P. R.. Democratic Brazil: Actors, Institutions and Processes. Pittsburgh: University of Pittsburgh Press.

2004. The Political Logic of Decentralization in Brazil. In: MONTERO, A.; SAMUELS, D. (orgs). Decentralization and Democracy in Latin America. Notre Dame: University of Notre Dame Press. 
SANTOS, A. M. Topografia do Brasil profundo: votos, cargos e alinhamentos nos municípios brasileiros. Opinião Pública, vol. 19, n. 1, pp. 1-20, 2013.

SCHEUFELE, D. A.; SHANAHAN, J.; KIM, S. H. 2002. Who cares about local politics? Media influences on local political involvement. J\&MC Quarterly, vol. 79, n. 2, pp. 427-444.

SCOTT, J. C. 1999. Seeing Like a State. New Haven: Yale University Press.

SOARES, G. A. D.; TERRON, S. 2008. Dois Lulas: a geografia eleitoral da reeleição (explorando conceitos, métodos e técnicas de análise geoespacial). Opinião Pública, vol.14, n. 2, pp.269-301, 2008.

SPECK, B.; CERVI, E. U. Dinheiro, tempo e memória eleitoral: Os mecanismos que levam ao voto nas eleições para prefeito em 2012. DADOS - Revista de Ciências Sociais, vol. 59, n. 1, pp. 53-90, 2016.

TERRON, S. 2012. Geografia Eleitoral em Foco. Em Debate, vol. 4., n. 2, pp. 8-18.

THERBORN, G. 2006. Why and How Place Matters. In: GOODIN, R. E.; TILLY, C. (eds). The Oxford Handbook of Contextual Political Analysis. New York: Oxford Univ. Press.

THRIFT, N. J. 2006. Space, Place and Time. In: GOODIN, R. E.; TILLY, C. (eds). The Oxford Handbook of Contextual Political Analysis. New York: Oxford University Press.

TROUNSTINE, J. 2009. All Politics Is Local: The Reemergence of the Study of City Politics. Perspectives, vol. 7, n. 3 .

VASQUEZ, V. Ao vencedor, a prefeitura: competição em eleições municipais (1996-2012). Dissertação de Mestrado. Programa de Pós-Graduação em Ciência Política, IFCH/UNICAMP, 2016.

VILLAÇA, F. 2012. Espaço Intra-Urbano no Brasil. São Paulo: Studio Nobel.

WONG, R. B. 2006. Detecting the Significance of Place. In: GOODIN, R. E.; TILLY, C. (eds). The Oxford Handbook of Contextual Political Analysis. New York: Oxford Univ. Press. 